Original Article

\title{
ALPHA AMYLASE AND ALPHA GLUCOSIDASE INHIBITION ACTIVITY OF SELECTED EDIBLE SEAWEEDS FROM SOUTH COAST AREA OF INDIA
}

\author{
P. REKA ${ }^{1 *}$, THAHIRA BANU A. ${ }^{2}$, M. SEETHALAKSHMI ${ }^{3}$ \\ 1,2Department of Home Science, ${ }^{3}$ Faculty of Agriculture and Animal Husbandry, Gandhigram Rural Institute (DU), Dindigul District, \\ Tamilnadu, India 624302 \\ Email: reka.vijivelu@gmail.com
}

Received: 11 Feb 2017 Revised and Accepted: 20 Apr 2017

\section{ABSTRACT}

Objective: The present work was to investigate the alpha amylase and alpha-glucosidase inhibitory activity of the selected edible seaweeds.

Methods: The seaweeds namely Acanthophora spicifera, Gracilaria corticata, Gracilaria edulis, Ulva lactuca and Ulva reticulata were selected for this study. Six and eight hours of ethanol and aqueous extract were used for the estimation of alpha amylase using DNS method and alpha-glucosidase inhibition activity.

Results: The study reported that the solvent from ethanol and aqueous in eight hours of extraction showed a higher inhibitory activity than six hours of extraction. Maximum of $89.1 \pm 0.96$ and $79.55 \pm 3.08$ percent of alpha-amylase and alpha-glucosidase inhibition activity were detected in the eight hours of aqueous extract $(0.5 \mathrm{ml})$ of Ulva reticulata and Gracilaria edulis respectively. All the selected edible seaweeds had significant differences $(p<0.05)$ in alpha amylase and alpha glucosidase inhibition activity between the selected seaweeds with different extracts.

Conclusion: It was concluded that all the selected edible seaweeds have the potential to act as a potent inhibitor of the carbohydrate hydrolyzing enzyme. Thus, it was clear from the study that seaweeds incorporated in small amounts in the dishes consumed in the daily diet can bring a control on postprandial blood glucose level.

Keywords: Seaweeds, Ulva reticulata, Aqueous, Alpha-amylase, Carbohydrate, Anti-diabetic activity, Blood glucose level

(C) 2017 The Authors. Published by Innovare Academic Sciences Pvt Ltd. This is an open access article under the CC BY license (http://creativecommons.org/licenses/by/4.0/) DOI: http://dx.doi.org/10.22159/ijpps.2017v9i6.17684

\section{INTRODUCTION}

Diabetes mellitus is a chronic disease, which occurs when the pancreas does not produce enough insulin or when the body cannot efficiently utilize the insulin, it produces [1]. This leads to an increased concentration of glucose in the blood. Diabetes is a significant public health threat and responsible for various long-term complications such as retinopathy, nephropathy and neuropathy leading to severe socio-economic problems throughout the world [2].

According to International Diabetes Federation [3] the prevalence of diabetes among adults (aged 40-59 y) in the world was 382 million in 2013 and this will increase up to 592 million in 2035. Recent national ICMR-INDIAB study reported that more than 62.4 million people are affected with diabetes in India and around 77.2 million people have pre-diabetes. In Tamilnadu, around 4.8 million people are affected with diabetes and 3.9 million people have pre-diabetes [4]

Diabetes requires changes for a lifetime. An important goal of treatment is to provide the patient with the necessary tools to achieve the best possible control of glycemia, lipidemia and blood pressure to prevent, delay or arrest the microvascular and macrovascular complications of diabetes while minimizing hypoglycemia and excess weight gain $[5,6]$.

The approach for controlling postprandial hyperglycemia is to inhibit the carbohydrate hydrolyzing enzymes such as alpha amylase and alpha glucosidase in the digestive system [7]. Alpha-amylase is involved in the breakdown of long chain carbohydrate and alpha glucosidase breaks down starch and disaccharides to glucose [8]. Inhibition of these enzymes helps to reduce the rate of carbohydrate digestion and cause a reduction in the rate of absorption thereby lowering the postprandial serum glucose levels $[9,10]$.

The majority of the people in developing countries depend on alternative therapies including natural resources for their primary health care [11]. Zeng Sun and Feng Chen [2] reported that antidiabetic agents from natural sources have attracted more and more attention because the clinical trials of several synthetic anti-diabetic drugs have been terminated due to safety concerns. In recent years many marine resources have attracted attention in the search for bioactive compounds to develop new drugs and health foods [12, 13]. Seaweeds are primitive non-flowering plants without root, stem and leaves. They comprise one of the commercially important marine renewable resources [14-16]. Many types of seaweeds have been traditionally used as food in Japan and New Zealand [17] Seaweeds are a good source of dietary fibres, polysaccharide, polyphenols, polyunsaturated fatty acids, minerals and vitamins. Which possess various biological activities like anti-diabetic, antiinflammatory, antioxidant activity, antibacterial, anticoagulant antiviral and apoptotic activity $[18,19]$. Seaweeds contain a prolific source of bioactive compounds that can be exploited for the treatment of major chronic diseases like diabetes through the inhibition of starch digesting enzymes and the regulation of glucoseinduced oxidative stress [20].

Recently, several studies reported that seaweeds can be potential interest for the development of novel drugs, functional foods and pharmaceutical applications. Hence, keeping the above facts in mind, present study was aimed to evaluate the alpha amylase and alpha glucosidase inhibitory activity of selected five edible seaweeds such as Acanthophora spicifera (Family-Rhodomelace), Gracilaria corticata (Family-Gracilariacea), Gracilaria edulis (FamilyGarcilariacea) from red seaweeds, Ulva lactuca (Family-Ulvaceae) and Ulva reticulata (Family-Ulvaceae) from green seaweeds.

\section{MATERIALS AND METHODS}

\section{Sample collection}

Five seaweeds namely Acanthophora spicifera, Gracilaria corticata, Gracilaria edulis, Ulva lactuca and Ulva reticulata were collected from the south coast area Rameswaram, Tamilnadu, India. The morphological characteristics namely type, colour, texture, shape and habitat of the collected seaweeds were observed and the taxonomical classification of the selected seaweed species was carried out 
according to Fritsch [21] and also the collected edible seaweeds were identified by Scientist from Central Salt and Marine Chemicals Research Institute, Mandapam camp, Ramanathapuram, Tamil Nadu, India. Gulf of Mannar, a marine province situated between India and Srilanka. It runs on its Indian side at its head from Pamban islands, a southern coastline that includes the famous pilgrim center Rameswaram to Kanyakumari [22-24]. The collected seaweeds were individually washed and dried. The dried samples were powdered and stored in the high-density polyethylene cover (HDPE).

\section{Sample preparation}

The powdered samples were used for the preparation of the extract with the solvents like ethanol and aqueous $(1: 10)$ at $37{ }^{\circ} \mathrm{C}$ temperature for six and eight hours at the water bath incubator shaker. The final extract was obtained filtered by what man No.1 filter paper and the filtrate was stored in refrigerator condition, which was used for estimation of alpha-amylase and alpha glucosidase inhibition activity.

\section{Inhibition of alpha-amylase activity}

The inhibition assay was performed according to Miller [25] using DNS method. Aqueous and ethanol extract of seaweed concentration in $0.5 \mathrm{ml}$ were added to $0.5 \mathrm{ml}$ of $0.02 \mathrm{M}$ sodium phosphate buffer (pH6.9 containing $6 \mathrm{mmol}$ sodium chloride) containing 0.04 units of the $\alpha$-amylase solution and were incubated at $37^{\circ} \mathrm{C}$ for $10 \mathrm{~min}$. After inhibition, $0.5 \mathrm{ml}$ of $1 \%$ starch solution in $0.02 \mathrm{M}$ sodium phosphate buffer $\left(\mathrm{P}^{\mathrm{H}} 6.9\right)$ was added to each tube. The reaction was stopped with $1.0 \mathrm{ml}$ of $3,5 \mathrm{DNSA}$ reagent. The test tubes were incubated in a boiling water bath for $5 \mathrm{~min}$, then cooled down to room temperature. The reaction mixture was diluted by the addition of 10 $\mathrm{ml}$ distilled water and absorbance was then measured at $540 \mathrm{~nm}$. The control samples were also prepared accordingly without any seaweed extracts and were compared with the test samples containing various concentrations of the seaweed extracts prepared with different solvents. The results were expressed as a percentage (\%) inhibition calculated using the formula:

$$
\text { Inhibition (\%) } \frac{\mathrm{Abs}(\mathrm{C})-\mathrm{Abs}(\mathrm{Ex})}{\mathrm{Abs}(\mathrm{C})} \times 100
$$

Where Abs (C) is the absorbance of the control (without extract or standard) and Abs (Ex) is the absorbance in the seaweed extracts or standard.

\section{Inhibition of alpha-glucosidase activity}

The inhibitory activity was determined by incubating a solution of starch substrate $(2 \% \mathrm{w} / \mathrm{v}$ maltose or sucrose) $1 \mathrm{ml}$ with $0.2 \mathrm{M}$ Tris buffer $\mathrm{pH} 8.0$ and seaweed extract for $5 \mathrm{~min}$ at $37^{\circ} \mathrm{C}$. The reaction was initiated by adding $1 \mathrm{ml}$ of alpha-glucosidase enzyme $(1 \mathrm{U} / \mathrm{ml})$ to it followed by incubation for $40 \mathrm{~min}$ at $35^{\circ} \mathrm{C}$. Then the reaction was terminated by the addition of $2 \mathrm{ml}$ of $6 \mathrm{~N} \mathrm{HCl}$. Then the intensity of the colour was measured at $540 \mathrm{~nm}$ [26].

$$
\text { Inhibition (\%) } \frac{\operatorname{Abs}(\mathrm{C})-\mathrm{Abs}(\mathrm{Ex})}{\mathrm{Abs}(\mathrm{C})} \times 100
$$

Where Abs (C) is the absorbance of the control (without extract or standard) and Abs (Ex) is the absorbance in the seaweed extracts or standard.

\section{Statistical analysis}

The alpha-amylase and alpha glucosidase inhibitory activity were performed in triplicate and mean and standard deviation values were calculated. One way ANOVA followed by a Duncans multiple range test at $\mathrm{p}<0.05$ using SPSS version 16 to detect the significant differences among the selected seaweeds different extracts.

\section{RESULTS}

\section{Inhibition of alpha-amylase activity of selected seaweeds}

The result of alpha-amylase inhibition activity is presented in table 1. Maximum inhibition $89.1 \pm 0.96$ percent of alpha amylase was detected in eight hours of aqueous extracts of Ulva reticulata. According to the statistical results, the alpha-amylase inhibitory activity of the Ulva reticulata in eight hours of the aqueous extract was significantly varied among the selected seaweeds with different extracts except for the eight hours of aqueous extracts of Gracilaria corticata, Gracilaria edulis, Ulva lactuca and the six hours aqueous extracts of the Gracilaria edulis. While in the six hours of aqueous extract of Ulva reticulata showed $81.96 \pm 1.00$ percent. The inhibitory activity of Ulva lactuca found to be $50.9 \pm 0.36$ and $59.66 \pm 3.91$ in six and eight hours of ethanol extracts respectively. Aqueous extract of Ulva lactuca showed $80.53 \pm 5.00$ and $83.43 \pm 2.5$ in six and eight hours respectively.

Red seaweeds such as Acanthophora spicifera, Gracilaria corticata and Gracilaria edulis showed 27.96 $\pm 1.05,62.96 \pm 1.69$ and $60.26 \pm 0.9$ percent in six hours and $38.8 \pm 6.6,66.36 \pm 4.29$ and $75.06 \pm 4.20$ in eight hours of ethanol extracts respectively. Whereas in aqueous extract it was found to be $49.5 \pm 1.73,80.43 \pm 2.5$ and $85.2 \pm 1.83$ percent in Acanthophora spicifera, Gracilaria corticata and Gracilaria edulis extracts taken from six hours and 54.73 $\pm 5.10,84.66 \pm 1.59$ and $87.86 \pm 3.4$ percent of inhibition detected in the extracts taken eight hours of extraction respectively. Acanthophora spicifera had less inhibition of alpha-amylase activity than the Gracilaria edulis and Gracilaria corticata. The statistical results showed the alpha-amylase inhibition was significantly varied $(\mathrm{p}<0.05)$ in Acanthophora spicifera in six and eight-hour ethanol extract between the selected seaweeds with different extracts.

Table 1: Alpha-amylase inhibitory activity of selected seaweeds

\begin{tabular}{llll}
\hline Nam of the seaweed & Ethanol extract & Aqueous extract \\
\cline { 2 - 4 } & Six h extraction & Eight h extraction & Six h extraction \\
\hline Acanthophora spicifera & $27.96 \pm 1.05^{\mathrm{a}}$ & $38.8 \pm 6.6^{\mathrm{b}}$ & $49.5^{\mathrm{b}} \pm 1.75^{\mathrm{c}}$ \\
Gracilaria corticata & $62.96 \pm 1.69^{\mathrm{ef}}$ & $66.36 \pm 4.29^{\mathrm{f}}$ & $80.43 \pm 2.5^{\mathrm{gh}}$ \\
Gracilaria edulis & $60.26 \pm 0.9^{\mathrm{de}}$ & $75.06 \pm 4.20^{\mathrm{g}}$ & $85.2 \pm 1.83^{\mathrm{hij}}$ \\
Ulva lactuca & $50.9 \pm 0.36^{\mathrm{c}}$ & $59.66 \pm 3.91^{\mathrm{de}}$ & $84.66 \pm 1.59^{\mathrm{hij}}$ \\
Ulva reticulata & $51.03 \pm 2.32^{\mathrm{c}}$ & $53.46 \pm 4.96^{\mathrm{c}}$ & $87.86 \pm 3.4^{\mathrm{hjk}}$ \\
\hline
\end{tabular}

Values represent the mean of three replicates. Values are given as mean \pm SD. Values with different alphabets are indicated that the significant differences seen $(\mathrm{p}<0.05)$ between the selected seaweeds with different extracts.

\section{Inhibition of alpha glucosidase activity of seaweeds}

The alpha glucosidase activity of the selected seaweeds presented in fig. I. Acanthophora spicifera showed $32.0 \pm 2.5$ and $42.7 \pm 4.9$ percent of inhibition in six hours of extraction with ethanol and aqueous solvents respectively. Whereas in extracts taken from eight hours of ethanol and aqueous extract it showed $37.08 \pm 2.5$ and $46.86 \pm 10.8$ percent respectively. The statistical results showed the alpha glucosidase inhibition was significantly varied $(p<0.05)$ in
Acanthophora spicifera in eight-hour ethanol extract between the selected seaweeds with different extracts.

Gracilaria corticata showed $51.14 \pm 8.61$ and $64.34 \pm 0.76$ percent in six hours and $56 \pm 2.68$ and $73.53 \pm 3.4$ percent in eight hours of ethanol and aqueous extract respectively. Gracilaria edulis exhibited $55.68 \pm 12.3$ and $71.91 \pm 2.35$ percent of inhibition in six hours of ethanol and aqueous extract respectively. While in eight hours of ethanol and aqueous extraction, it was found to have $77.5 \pm 2.04$ and $79.55 \pm 3.08$ percent 
respectively. The statistical results showed the alpha glucosidase inhibition was significantly varied $(\mathrm{p}<0.05)$ in Gracilaria edulis in eighthour aqueous extract between the selected seaweeds with different extracts except the eight-hour aqueous extracts of Ulva reticulata and six-hour aqueous extracts of Gracilaria edulis.

The alpha glucosidase inhibition activity of Ulva lactuca was $50.42 \pm 3.8$ and $65.71 \pm 1.21$ in six and eight hours of ethanol extract respectively. Whereas in aqueous extract of Ulva lactuca from six and eight hours extraction showed $43.5 \pm 8.5$ and $61.81 \pm 1.83$ percent of alpha glucosidase inhibition respectively. In Ulva reticulata it was found to be $30.3 \pm 2.1$ and $43.5 \pm 4.78$ percent in six and eight hours of ethanol extract taken from extraction respectively. Whereas it showed $67.4 \pm 4.73$ percent inhibition in six hours and $79.55 \pm 3.08$ percent of inhibition in the extract of eight-hour extraction using aqueous solvent. The statistical results showed the alpha glucosidase inhibition was significantly varied at $\mathrm{p}<0.05$ percent between the seaweeds with different extracts.

The alpha-amylase and alpha glucosidase activities of the selected seaweeds were found to be in the range from $27.96 \pm 1.05$ to $89.1 \pm 0.96$ and $32.0 \pm 1.5$ to $79.55 \pm 3.08$ respectively. The maximum inhibition of alpha-amylase and alpha glucosidase activity were detected in the eight hours of aqueous extracts of Ulva reticulata and Gracilaria edulis respectively. The minimum inhibition was detected in Acanthophora spicifera. The study reported that all the selected edible seaweeds have the capacity to inhibit alpha-amylase and alpha glucosidase activity. The standard Acarbose showed 58.2 \pm 1.2 and 78.4 \pm 0.5 percent of alpha-amylase and alpha glucosidase inhibition respectively.

Table 2: Alpha glucosidase inhibitory activity of selected seaweeds

\begin{tabular}{llll}
\hline Nam of the seaweed & Ethanol extract & Aqueous extract \\
\cline { 2 - 4 } & Six h extraction & Eight h extraction & Six h extraction \\
\hline Acanthophora spicifera & $32.0 \pm 2.5^{\mathrm{a}}$ & $37.08 \pm 2.5^{\mathrm{b}}$ & $42.7 \pm 4.9^{\mathrm{c}}$ \\
Gracilaria corticata & $51.14 \pm 8.61^{\mathrm{d}}$ & $56 \pm 2.68^{\mathrm{e}}$ & $64.34 \pm 0.76^{\mathrm{fg}}$ \\
Gracilaria edulis & $55.68 \pm 12.3^{\mathrm{e}}$ & $71.91 \pm 2.35^{\mathrm{h}}$ & $77.5 \pm 2.04^{\mathrm{ij}}$ \\
Ulva lactuca & $50.42 \pm 3.8^{\mathrm{d}}$ & $65.71 \pm 1.21^{\mathrm{fg}}$ & $43.5 \pm 8.5^{\mathrm{c}}$ \\
Ulva reticulata & $30.3 \pm 2.1^{\mathrm{a}}$ & $43.5 \pm 4.78^{\mathrm{c}}$ & $73.53 \pm 3.4^{\mathrm{hi}}$ \\
\hline
\end{tabular}

Values represent the mean of three replicates. Values are given as mean \pm SD. Values with different alphabets are indicated that the significant differences seen $(\mathrm{p}<0.05)$ between the selected seaweeds with different extracts.

\section{DISCUSSION}

The dramatic increase in the incidence of type 2 diabetes represents one of the most significant global health issues of the Twenty-first century has prompted revisions in the prevention and treatment of this devastating disease [27]. Two enzymes that play a key role in diabetes are alpha amylase and alpha glucosidase. Alpha-amylase catalyzes the hydrolysis of starch to a mixture of smaller oligosaccharides consisting of maltose, maltotriose and oligo glucans and it is further degraded to glucose by $\alpha$-glucosidase after which they are absorbed into the bloodstream [28]. Inhibition of alpha glucosidase enzyme activity leads to a reduction in disaccharide hydrolysis that has beneficial effects on glycemic index control in diabetic patients [29, 30]. Recent studies have also shown that marine algae contain a wide range of highly bioactive secondary metabolites with therapeutic potential that might represent useful leads in the development of functional ingredients for nutraceuticals, cosmeceuticals, and pharmaceuticals [31-33].

In the present study, the anti-diabetic activity of five edible seaweeds collected from the Gulf of Mannar was evaluated. The south coast of Tamil Nadu in India is a unique marine habitat infested with diverse seaweeds. Seaweeds are the extraordinary, sustainable resources in the marine ecosystem that have been used as a source of food, medicine and industrial products [34].

Three seaweeds from red algae (Acanthophora spicifera, Gracilaria corticata and Gracilaria edulis) and two seaweeds from green algae (Ulva lactuca and Ulva reticulata) used in this study. Alpha-amylase and alpha glucosidase inhibition activity were identified using the solvents like ethanol and aqueous in six and eight $\mathrm{h}$ of extraction.

$\mathrm{Xu}$ [35] reported that seaweeds are known to contain alpha glucosidase and alpha amylase inhibitors. The study reported that all the selected seaweed extracts found have a valuable amount of alpha amylase and alpha glucosidase inhibitory capacity. The in vitro alpha amylase and alpha glucosidase activity of aqueous extracts of seaweeds showed a higher degree of inhibitory activity than ethanol extract. The study compares the anti-diabetic activity with the duration of solvent extraction of six and eight $\mathrm{h}$ and it is reported that the eight $\mathrm{h}$ extraction of both solvents namely ethanol and aqueous were found to have an increased inhibition of alphaamylase and alpha glucosidase activity than the six $h$ of extraction.

Zheng and Feng Chen [2] evaluated the inhibitory effects of green algae Chollrella pyrenoidasa possessed moderate alpha-amylase inhibitory activity and strong alpha glucosidase inhibitory activity and concluded that the green algae considered as a potential functional food for diabetic patients.

In the study conducted the maximum inhibition of alpha-amylase and alpha glucosidase was recorded in the Ulva reticulata and Gracilaria edulis followed by Ulva lactuca and Gracilaria corticata in extracts of eight-hour extraction in both solvents. It is clear that at the time of extraction increases the activity as increased this indicates that seaweed required a longer time to release the phytochemicals and colloids from its tissues. The alpha-amylase inhibitory activity of the selected seaweed extracts showed the higher inhibition compare, then the standard Acarbose except for the Acanthophora spicifera. However, the alpha glucosidase inhibitory activity of the standard Acarbose was higher than the selected seaweeds extracts except the Gracilaria edulis with eight h of aqueous extracts.

Ulva species are used as a traditional food in many Asian countries. In Japan, they are included in a variety of dishes such as salads, soups, cookies, meals and condiments as well as a mixed product with other green macroalgae [36,37]. Soluble fiber levels are high in Ulva Species from 20 to 40 percent of dry weight. Recently several studies reported that Ulva could be of potential interest for food, development of novel drugs and functional foods, pharmaceutical and agricultural applications $[38,39]$.

Lakshmana Senthil [40] on screening the alpha-amylase inhibitory activity using different solvents in ten seaweeds from the southeast coastal area of India found that the ethyl extracts of C. ramcemosa, G. gracilis, $\mathrm{C}$. harnemanii and P. gymnospora showed potent alpha-amylase inhibitory activity. Among all the seaweeds Gracilaria edulis showed inhibition activity of $57 \pm 0.9,53 \pm 0.1$ and $60 \pm 1.2$ in extracts taken from different solvents like methanol, acetone and ethyl acetate respectively. This study also determined the effective percent of inhibition detected in ethanol and aqueous extracts of Gracilaria edulis.

Hang Wang [41] stated that a diet rich in marine products lowers the incidence of diabetes, cancer and obesity. Lucy [42] reported that the polyphenolic-rich extracts from edible seaweed may have anti-diabetic effects due to their ability to inhibit certain digestive enzymes and were responsible for the stimulation on glucose uptake $[43,44]$.

In the present study, it is clear that seaweeds may take a longer time to digest and stays for a longer period of time in the gastro intestine and the fiber and phenolic contents may interfere with the absorption which in turn delays rise in blood glucose levels. Min Sun 
Kim [44] evaluated the physiological effects of seaweed supplementation in subjects with diabetes mellitus. Subjects were randomised into either a control group or an experimental group. Pills with equal parts of sea tangle and sea mustard (48 gm) were provided to the experimental group three times in a day for four weeks and the study reported that the fasting blood glucose levels and two-hour postprandial blood glucose measurements were decreased significantly in the experimental group. This study concludes that ingestion of seaweed influences glycemic control, lower blood lipids and increased antioxidant enzyme activities.

Henrinksen [45] reported that oxidative stress known to play a significant role in the development and progression of diabetes mellitus. Free radicals, including superoxide's and hydroxyl radicals, induce the structural modification and functional impairment of key molecules during the glycation process, leading to the onset of diabetes mellitus [46]. Algal polysaccharides have demonstrated to play an important role as free radical scavengers for the prevention of damage from oxidative stress in living organisms [35, 47-49]. A reduction in the Glycemic Index of starch-based foods can be obtained with the use of fibers, which could be beneficial to diabetic patients by aiding in the control of postprandial insulin release [50] Lahaye and Kafeer [51] stated that the carbohydrate content of algae is relatively high (33.75\% DM) but algae are not considered as an energy rich food because the digestibility of these carbohydrates is low.

Suhaila Mohamed [52] reported that most of the seaweeds contain high levels of soluble dietary fibers (carrageenan, agar, alginates). They possess a wide range of beneficial physiological functions, including increased satiety; increased gut transit time reduced cholesterol and glucose absorption in the gastrointestinal tract and reduced risk of coronary heart disease. Above studies are clear that several types of seaweeds are rich in dietary fiber and other secondary metabolites and their mechanism, it may be responsible for the potential anti-diabetic activity of the seaweeds, which inhibit the alpha amylase, and alpha glucosidase activity.

\section{CONCLUSION}

Diabetes mellitus is a global health threat among the degenerative diseases. To regulate the postprandial glucose level is important in the treatment of diabetes mellitus. The inhibition of key enzymes of carbohydrate digestion such as alpha amylase and alpha glucosidase helps to maintain the postprandial blood glucose level. Most of the studies have reported that seaweeds possess an inhibitory activity of the enzymes due to their soluble fiber, phenolic compounds and other pharmaceutical compounds. It may act as a low glycemic index food ingredient and help to maintain a blood glucose level through slow digestion and absorption. From the study, it is concluded that all the selected seaweeds possess an inhibitory activity of alpha amylase and alpha glucosidase. It can be used as a functional food in product development to maintain the postprandial blood glucose, which may prevent or delay the complications related diabetes.

\section{CONFLICT OF INTERESTS}

Declared none

\section{REFERENCES}

1. Danaei G, Finucane MM, Lu Y, Singh GM, Cowan MJ, Paciorek CJ, et al. National, regional, and global trends in fasting plasma glucose and diabetes prevalence since 1980: systematic analysis of health examination surveys and epidemiological studies with 370 country-years and 2.7 million participants. Lancet 2011;378:31-40.

2. Zhen Sun, Feng Chen. Evaluation of the green algae Chlorella pyrenoidosa for the management of diabetes. J Food Drug Anal 2012;20:246-9.

3. International Diabetes Federation. IDF diabetes atlas. $6^{\text {th }}$ edition. www.idf.org/diabetesatlas; 2013.

4. Anjana RM, Pradeepa R, Deepa M, Datta M, Sudha V, Unnikrishan R, et al. For the ICMR-INDIAB collaborative Study Group. Prevalence of diabetes and pre-diabetes in urban and rural India: phase I results of ICMR-INDIAB STUDY. Diabetol 2011;54:3022-7.
5. American Diabetes association. Standards of medical care for patients with diabetes mellitus (position statement). Diabetes Care 2002;25:S33.

6. Kathleen Mahan, Sylvia Escott-Stmp. Krause's food, Nutrition and diet therapy, Elsevier, USA; 2004.

7. Shailimavardhini RD, Reddinaik B, Neelima M, Ramesh B. Screening and production of $\alpha$-amylase from Aspergillus niger using zero value material for solid state fermentation. Int J Pharm Pharm Sci 2005;5:55-60.

8. Sindhu S, Nair, Vaibhavi Kavrekar, Anshu Mishra. In vitro studies on alpha amylase and alpha glucosidase inhibitory activity of selected plant extracts. Eur J Exp Biol 2013;3:128-32.

9. Bhat M, Zinjarde SS, Bhargava SY, Kumar AR, Joshi BN. Antidiabetic Indian plants: a good source of potent amylase Inhibitors. J Evidence-Based Complementary Altern Med 2011;810. http://dx.doi.org/10.1093/ecam/nen040

10. Tarling CA, Woods K, Zhang R, Brastanos HC, Brayer GD, Andersen RJ, et al. The search for novel human pancreatic alpha-amylase inhibitors: high-through screening of terrestrial and marine natural product extract. Chem Biol 2008;9:433-8.

11. Hasan Z, Yam MF, Ahemad Yusof AP. Anti-diabetic properties and mechanism of action of Gynura procumbens water extract in streptozotocin-induced diabetic rats. Molecules 2010;15:9008-23.

12. Liu L, Yu YL, Liu C, Wang XT, Liu XD, Xie L. Insulin deficiency induces abnormal increases in intestinal disaccharides activities and expression under diabetic states: evidences from in vivo and in-vitro study. Biochem Phamacol 2011;82:1963-70.

13. Sun HH, Mao WJ, Jiao JY, Xu JC, Li HY, Chen Y, et al. Structural characterization of extracellular polysaccharides produced by the marine fungus Epicoccun nigrum JJY-40 and their antioxidant activities. Mar Biol 2011;13:1048-55.

14. Kamaladhasan N, Subramanian SK. Influence of seaweed liquid fertilizers on legume crop, red gram. J Basic Appl Biol 2009;3:21-4.

15. Selvaraj K, Murugalakshmikumari R, Ramasubramanian V. Bio removal of nickel using seaweed as bio adsorbent. J Basic Appl Biol 2010;4:207-12.

16. Domettila C, Brintha TSS, Sukumaran S, Jeeva S. Diversity and distribution of seaweeds in the muttom coastal waters, southwest coast of India. Biodivers J 2013;4:105-10.

17. Kunihisa Iwai. Antidiabetic and antioxidant effects of polyphenols in brown algae Ecklonia Stolonifera in generally diabetic KK-Ay mice. Plant Foods Hum Nutr 2008;63:163-9.

18. Kim AR, Shin TS, Lee MS, Park JY, Park KE, Yoon NY, et al. Isolation and identification of phlorotannins from Ecklonia stolonifera with antioxidant and anti-inflammatory properties. J Agric Food Chem 2009;57:3483-9.

19. Chaturedi M, Sing M, Kumar R, Chungh MR. A diet with nutritional, medicinal and industrial value. Res J Med Plants 2011;5:153-7.

20. Lee SH, Han JS, Hea SJ, Hwang JY, Jeon YJ. Protective effects of dickol isolated from Eclonia cava against high glucose-induced oxidative stress in human umblical endothelial cells. Toxicol In Vitro 2010;24:375-81.

21. Fritsch FE. The structure and reproduction of algae. Vol. 1. University Press Cambridge; 1935. p. 1-791.

22. Mary Josephine M, Usha R, Maria Victorial Rani S. Current status of seaweed diversity and their seasonal availability at Haare Island, Gulf of Mannar. Sci Res Repot 2013;3:146-51.

23. Chacko P, Mahadevan S, Ganesan R. A guide to the field study of the fauna and flora of Krusadi Islan, Gulf of Mannar. Contr Mar Biol 1995;3:1-16.

24. Kaliaperumal N, Kalimuthu S, Ramalingam JR. Economically important seaweeds. M Devaraj. Ed. Special 62. Central Marine Fisheries Research Institute. In Coun of Agric Res; 1955. p. 1-35.

25. Miller GL. Use of dinitro salicylic acid reagent for determination of reducing sugar. Analy Chem 1959;31:426-8.

26. Krisnaveni S, B Theymoli, S Sadasivam. Sugar distribution in sweet stalk sorghum. Food Chem 1984;15:229.

27. DeVille-Almond J, Tahrani AA, Grant J, Gray M, Thomas GN, Taheri S. Awareness of obesity and diabetes: a survey of a subset of british male drivers. Am J Mens Health 2011;5:30-7.

28. Gomathi D, Kalaiselvi M, Uma C. In vitro alpha amylase and alpha glucosidase inhibitory effects of ethanolic extract of Evolvulus alsinoides (L.). Int Res J Pharm 2012;3:226-9. 
29. Gin H, Rigalleau V. Postprandial hyperglycemia and diabetes. Diabetes Metab 2000;54:265-72.

30. Notkins AL. Immunologic and genetic factors in type 1 diabetes. Am J Biochem 2002;277:4354-8.

31. Thomas NV, Kim SK. Beneficial effects of marine algal compounds in cosmeceuticals. Mar Drugs 2013;11:146-64.

32. Blunt JW, Copp BR, Keyzers RA, Munro MH, Prinsep MR. Marine natural products. Nat Prod Rep 2013;30:237-323.

33. Blunt JW, Copp BR, Keyzers RA, Munro MH, Prinsep MR. Marine natural products. Nat Prod Rep 2012;29:144-222.

34. John Peter Paul J, Mahadevi B. Distribution and seasonal variation of some caulerpa species (Green seaweed) in Thoothukudi Region, the Southeast coast of Tamilnadu, India. Int J Pure Appl Biosci 2014;2:135-8.

35. Xu N, Fan X, Yan X, Li X, Niu R, Tseng CK. Antibacterial bromophenols from the marine red algae Rhodomela confervoides. Phytochem 2003;62:1221-6.

36. Rodriguez AP, Mawhinney TP, Marie DR, Cruz-Suarez LEC. Chemical composition of cultivated macroalgae Ulva elathrata (Roth) c Agardh. Food Chem 2011;129:491-8.

37. Tabarsa M, Rezaei M, Ramezanpour Z, Waaland JR. Chemical compositions of the marine algae Gracilaria salicornia (Rhodophyta) and Ulva lactuca (Chlorophyta) as a potential food source. J Sci Food Agric 2012;92:2500-6.

38. Costa LS, Fedelis GP, Corderio SL, Oliveria RM, Sabry DA. Biological activities of sulfated polysaccharides from tropical macroalgaes. Biomed Pharmocother 2010;64:21-8.

39. Wijesekara I, Pangestuti R, Kim SK. Biological activities and potential health benefits of sulfated polysaccharides derived from marine algae. Carbohydra Polym 2011;84:14-21.

40. Lakshmana Senthil S, Vinothkumar T, Geatharamani D, Maruthupandi T. Screening of seaweeds collected from a southeast coastal area of India for A-amylase inhibitory activity, antioxidant activity and biocompatibility. Int J Pharm Pharm Sci 2013;5:240-4

41. Hang Wang, Zhi-Ming Fu, Chunn-Chao Han. The potential applications of marine bioactive against diabetes and obesity. Am J Marine Sci 2014;2:1-8.

42. Lucy Mohapata, Premalathatapati, Ramachandra Panigrahy, Asaubrat Kumar Bhattamisra. Therapeutic health booster: seaweeds against several maladies. In J Geo-Marine Sci 2013;42:538-46.

43. Kurihara H, Mitani T, Kawabata J, Takahashi K. Inhibitory potencies of bromophenols from rhodomelaceae algae against the a-glucosidase activity. Fish Sci 1999;65:300-3.

44. Min Sun Kim, Jung Yun Kim, Woong Hwan Choi, Sang Sun Lee. Effects of seaweed supplementation on blood glucose concentration, lipid profile and antioxidant enzymes activities in patients with type 2 diabetes mellitus. Nut Res Pract 2008;2:62-7.

45. Henriksen EJ, Diamond-Stanic MK, Marchionne EM. Oxidative stress and the etiology of insulin resistance and type 2 diabetes. Free Radical Biomed 2010;51:993-9.

46. Ardstani A, Yazdanparast R. Inhibitory effects of ethyl acetate extract Teucrium polium on In vitro protein glycoradation. Food Chem Toxicol 2007;45:2402-11.

47. Anastyuk SD, Shevchenko NM, Nazarenko EL, Dmitrenok PS, Zvyagintseva TN. Structural analysis of a fucoidan from the brown alga Fucus evanescens by MALDI-TOF and tandem ESI mass spectrometry. Carbohydr Res 2009;344:779-87.

48. El Gamal A. Biological importance of marine algae. Saudi Pharm J 2010;18:1-25.

49. Zhang Z, Wang F, Wang X, Liu X, Hou Y, Zhang Q. Extraction of the polysaccharides from five algae and their potential antioxidant activity in vitro. Carbohydr Polym 2010;82:118-21.

50. Roberts SB. High-glycemic index foods, hunger and obesity is there a connection. Nutr Rev 2000;58:163-9.

51. Lahaye M, Kafeer B. Seaweed dietary fibres: structure, physicochemical and biological properties relevant to intestinal physiology sciences des aliments. Lavoisier 1997;17:563-84.

52. Suhaila Mohamed, Siti Nadia Hashim, Hafeedza, Abdul Rahman Seaweeds: a sustainable functional food for complementary and alternative therapy. Trends Food Sci Technol 2012;23:83-96.

\section{How to cite this article}

- $\quad$ P Reka, Thahira Banu A, M Seethalakshmi. Alpha-amylase and alpha glucosidase inhibition activity of selected edible seaweeds from South coast area of India. Int J Pharm Pharm Sci 2017;9(6):64-68. 